\section{MECHANISM OF MATERIAL} REMOVAL DURING DIE-
SINKING EDM OF TOOL
STEEL EN $90 \mathrm{MnCrV} 8$

LUBOSLAV STRAKA, GABRIEL DITTRICH

Department of Automotive and Manufacturing Technologies Faculty of Manufacturing Technologies of the Technical University of Kosice with a seat in Presov, Presov, Slovakia

DOI : 10.17973/MMSJ.2020_06_2020026

luboslav.straka@tuke.sk

Mechanism of material removal after die-sinking electrical discharges machining, is quite complex. The principle is based on electrical discharge which occurs between workpiece and tool electrode. The electrical discharges always occur when complying the specific conditions, i.e. reaching the desired mutual distance (gap), mutual combination of main technological parameters and sufficient discharge energy. The size of discharge energy has a significant impact on the character of a crater in the workpiece and tool electrode. Desirable is only crater in the workpiece. The crater produced during one electric discharge in tool electrode is generally regarded as the negative site in die-sinking electrical discharges machining. The creation of this crater in the tool electrode has a direct effect on its wear. Paper aimed to describe the mechanism of material removal and its physical regularities of tool steel EN 90MnCrV8 (W.-Nr. 1.2842) in die-sinking electrical discharges machining.

KEYWORDS

Die-sinking Electrical Discharge Machining (Die-sinking EDM), Electrode Wear Ratio (EWR), Main Technological Parameters (MTP), Material Removal Rate (MRR) Tool Wear Rate (TWR).

\section{INTRODUCTION}

The formation of electrical discharges during die-sinking EDM occurs by points, or by surface in the place of the strongest electrical voltage. The actions of electrical discharges with high current density, the small particles are collected from the workpiece and electrode. In place of electrical discharge, the surface of the material rapidly heats [Straka 2016a], melts [Tothova 2015] and partially evaporates [Tavodova 2014]. In place of electrical discharge is expelled from the place of discharge by the material vapour to form a crater with a specific shape and size. Its size and a shape depends on workpiece and electrode material, discharge energy, properties of dielectric fluid [Banker 2013], but also on setting of main technological parameters (MTP) [Murcinkova 2013].

\section{FUNDAMENTALS OF A CRATER CREATION AFTER AN ELECTRICAL DISCHARGE}

The resulting product of one electrical discharge in die-sinking EDM is the formation of the crater in the workpiece, and also in the tool electrode [Straka 2016b]. However, the difference between the two craters is that the crater is desirable only in the workpiece [Baron 2016]. The crater produced during one electric discharge in tool electrode [Kiyak 2007] is generally regarded as the negative site in die-sinking EDM. The creation of this crater in the tool electrode has a direct effect on its wear [Straka 2016c]. A series of investigations have been conducted on tool electrode wear in die-sinking EDM. Soni and Chakraverti studied the surface quality, material removal rate, wear ratio, and dimensional accuracy in EDM of alloy steels [Soni 1995]. Singh investigated the effect of machining parameters on tool electrode wear in die-sinking EDM of En-31 tool steel with different electrode materials [Singh 2004]. Also, Luis et al. have carried out a study on tool electrode wear in die-sinking EDM of silicon carbide using the technique of design of experiments (DoE) [Luis 2005]. The crater, formed during one electric discharge in die-sinking EDM on workpiece and tool electrode [Micietova 2013], is generally regarded as the hemispherical segment.

It is generated by high-intensity of electric discharge. They are put into motion positive and negative ions (phase $t_{1}$ ). Their speed accelerates [Krenicky 2011] to the value at which occurs to the formation ionized channel (phase $t_{2}$ ). In this state, it begins between the workpiece and electrode to flow an electric current $I\left(10^{6} \mathrm{~A} . \mathrm{mm}^{-2}\right)$ which causes the electric discharge (phase $t_{3}$ ). The resulting plasma zone with very high temperatures (reaches up to $10000^{\circ} \mathrm{C}$ ) consequently causes melting [Dubjak 2016] and evaporating [Straka 2016d] of individual particles of material (phase $t_{4}$ ). A temperature drop due to the drop [Corny 2016] in current $I$ (phase $t_{5}$ ) causes the implosion of the bubbles, and thus the gas pressure drop, resulting in disruption of the material (cavitation) and formation of the crater. In this phase the discharge current $I$ and the voltage $U$ decreases to zero. The shape of formed crater, and its size, depends on MTP, properties of dielectric fluid, and type materials of workpiece [Panda 2016] and tool electrode. In phase $t_{6}$ is a state similar to phase $t_{1}$, and thus before discharge. Mechanism of material removal on workpiece and tool electrode in particular phases of discharge $\left(t_{1}\right.$ to $\left.t_{6}\right)$ during die-sinking EDM shows Fig. 1.

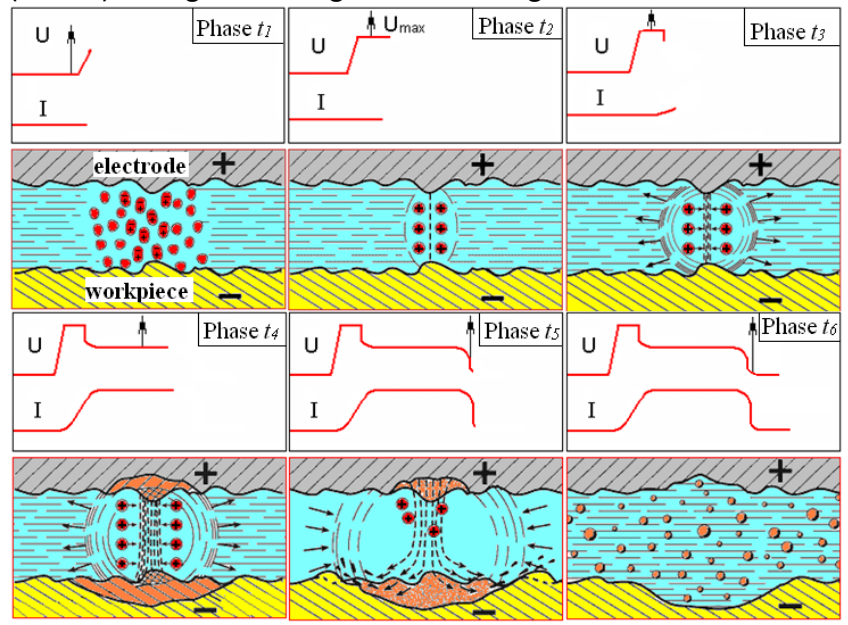

Figure 1: Mechanism of material removal on workpiece and tool electrode in particular phases of discharge $\left(t_{1}\right.$ to $\left.t_{6}\right)$ during die-sinking EDM

The shape of crater in the phase $t_{5}$ is defined mainly by its diameter and depth (Fig.2). Both of these characteristics are directly dependent on the MTP and properties of the dielectric fluid [Straka 2017]. The formation of crater on the tool electrode [Botko 2019] is generally regarded as the undesirable phenomenon [Han 2016], because it primarily contributes to the wear. In practice, it is therefore necessary to achieve that Material removal rate (MRR) was much bigger than the size of tool wear rate (TWR). It is necessary that the ratio MRR to TWR reached with die-sinking EDM as large as value " 1 ". Value ratio $M R R / T W R<1$ means the larger volume of the material removal from the workpiece as the tool electrode, which is undesirable. 

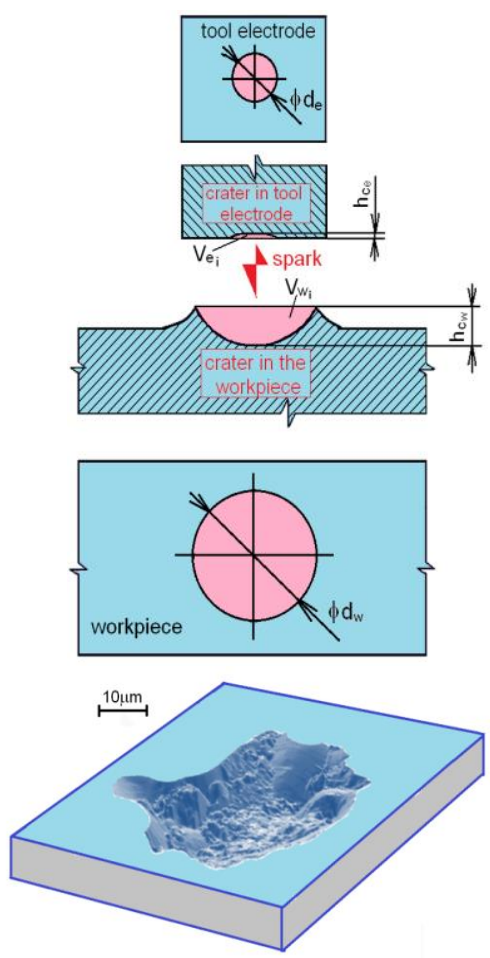

$V m(e)_{i}$ - material removal volume of workpiece (tool electrode), $h_{c w(e)}-$ crater depth in the workpiece (tool electrode), $d_{w(e)}-$ crater diameter in workpiece (tool electrode)

Figure 2: Volume and shape of crater after one discharge cycle in diesinking EDM

The volume of material removal from workpiece and too electrode during one of the discharge cycle of the die-sinking EDM can be determined according to the formula (1):

$$
V_{\text {total }}=k \cdot W_{\text {total }}
$$

where $V_{\text {total }}$ denotes total material removal volume of workpiece $V_{m i}$ and tool electrode $V_{e i}$ during one of the discharge cycle of the die-sinking EDM $\left(\mathrm{mm}^{3}\right), \mathrm{k}$ is proportionality factor, and $W_{\text {total }}$ is total energy of electrical discharge $(\mathrm{J})$.

The total volume material removal from the workpiece and the tool electrode depends mainly on the total energy of electric discharges which is determined by the MTP setting.

Accordingly the amount of material taken during a series of discharge cycles is proportional to the discharge energy that can be calculated according to the formula (2):

$$
W_{\text {total }}=\int_{0}^{t_{\text {on }}+t_{\text {off }}} U(t) \cdot I(t) d t
$$

where $W_{\text {total }}$ denotes total energy of electrical discharge $(\mathrm{J}), U(t)$ is electric voltage of discharge between workpiece and tool electrode in time $t(V), I(t)$ is peak current in time $t(A), t_{o n}(\mu s)$ is pulse on-time duration, and $t_{o f f}(\mu s)$ is pulse off-time duration.

By deriving integral Eq. 2 can be estimated energy electrical discharge for a particular discharge cycle according to the formula (3): $\quad W_{\text {cycle }}=U_{\text {cycle }} \cdot I_{\text {cycle }} \cdot\left(t_{\text {on }}+t_{\text {off }}\right)$

where $I_{\text {cycle }}$ denotes peak current of the particular discharge cycle $(A), U_{\text {cycle }}$ is voltage of discharge of the particular discharge cycle (V), $t_{o n}$ is pulse on-time duration of the

\begin{tabular}{|c|c|c|c|c|c|c|c|c|}
\hline \multirow{2}{*}{$\begin{array}{c}\text { Steel } \\
\text { designation }\end{array}$} & \multicolumn{8}{|c|}{ Chemical composition (\%) } \\
\hline & $\mathrm{C}$ & $\mathrm{Mn}$ & $\mathrm{Si}$ & \begin{tabular}{l|l}
$\mathrm{Cr}$ &
\end{tabular} & $\mathrm{Ni}$ & V & Pmax & Smax \\
\hline \multirow{4}{*}{ 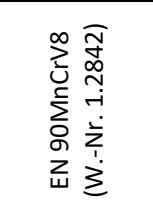 } & $0.75-0.85$ & $1.85-2.15$ & $0.15-0.35$ & $\max .0 .25$ & $\max .0 .35$ & 0.1-0.2 & 0.03 & 0.035 \\
\hline & \multicolumn{8}{|c|}{ Mechanical and physical properties } \\
\hline & \begin{tabular}{|c|} 
Tensile \\
strength \\
$R m(\mathrm{MPa})$
\end{tabular} & $\begin{array}{c}\text { Yield } \\
\text { strength } \\
R p_{0,2}(\mathrm{MPa})\end{array}$ & $\begin{array}{c}\text { Hardness in the } \\
\text { annealed condition } \\
\left(\mathrm{HB}_{\max }\right)\end{array}$ & $\begin{array}{c}\text { Hardness In } \\
\text { treated condition } \\
\left(\mathrm{HRC}_{\min }\right)\end{array}$ & $\begin{array}{l}\text { Specific heat } \\
\text { capacity } \\
\text { (J/kg.K) }\end{array}$ & $\begin{array}{c}\text { Thermal } \\
\text { conductivity } \\
(\mathrm{W} / \mathrm{m} . \mathrm{K}) \text { at } 20^{\circ} \mathrm{C}\end{array}$ & \begin{tabular}{|c|} 
Specific \\
electric resist. \\
$\left(\Omega . \mathrm{mm}^{2} / \mathrm{m}\right)$
\end{tabular} & $\begin{array}{c}\text { Electrical } \\
\text { conductivity } \\
\left(\text { Siemens.m } / \mathrm{mm}^{2} \text { ) }\right.\end{array}$ \\
\hline & 770.0 & 550.0 & 220.0 & 62.0 & 460.0 & 30.0 & 0.35 & 2.85 \\
\hline
\end{tabular}
Table 1: The main chemical, mechanical and physical properties of steel EN 90MnCrV8 (W.-Nr. 1.2842) 
Table 2 lists the basic mechanical and physical properties of material tool electrode EN CW004A.

Table 2: The basic mechanical and physical properties of material tool electrode EN CW004A

\begin{tabular}{|c|c|c|c|c|c|}
\hline $\begin{array}{c}\text { Material } \\
\text { designation }\end{array}$ & $\begin{array}{c}\text { Melting } \\
\text { point } \\
\left({ }^{\circ} \mathrm{C}\right)\end{array}$ & $\begin{array}{c}\text { Thermal } \\
\text { conductivity } \\
\left(\mathrm{W} . \mathrm{m}^{-1} \cdot \mathrm{K}^{-1}\right)\end{array}$ & $\begin{array}{c}\text { Electrical } \\
\text { conductivity } \\
\left(\mathrm{S} . \mathrm{m} . \mathrm{mm}^{-2}\right)\end{array}$ & $\begin{array}{c}\text { Tensile } \\
\text { strength } \\
(\mathrm{MPa})\end{array}$ & $\begin{array}{c}\text { Modulus } \\
\text { of elast. } \\
(\mathrm{GPa})\end{array}$ \\
\hline EN CW004A & 1083.0 & 390.0 & 58.0 & 220.0 & 130.0 \\
\hline
\end{tabular}

In the experiment was used electroerosive equipment PENTA 433 GS CNC by company Penta Trading Ltd. This is a CNC device [Michalik 2016] which is capable of operating in autonomous operation. Table 4 lists the basic technical parameters of electroerosive equipment PENTA 433 GS CNC.

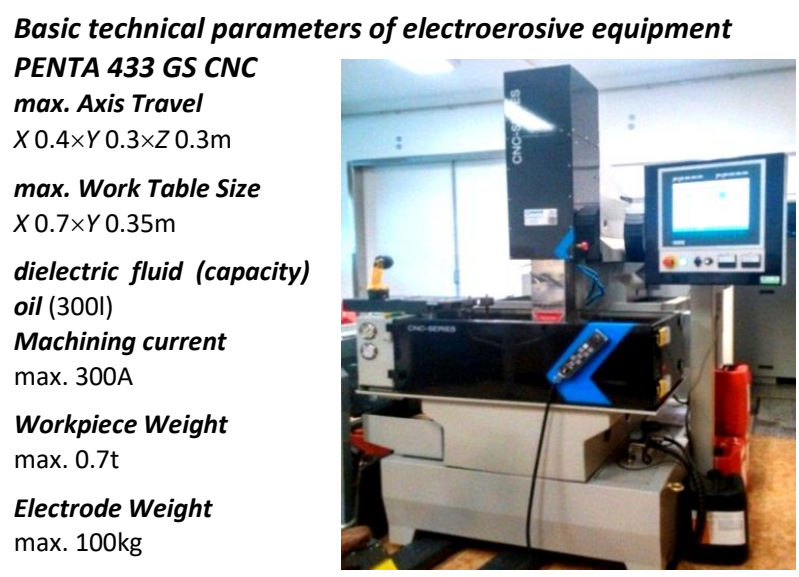

Figure 3: Die-Sinker EDM PENTA 433 GS CNC of Co. Penta Trading Ltd.

Parameter EWR, which comprehensively defines the quantity of material [Mathew 2014] taken from the tool electrode [Monka 2016] and the workpiece [Straka 2013], is substantially dependent on the setting of the MTP. Table 3 provides an overview of the MTP in die-sinking EDM of tool EN 90MnCrV8 (W.-Nr. 1.2842) with Cu-ETP electrode EN CW004A including limit settings used in the experiment.

Table 2: The range of setting the MTP in die-sinking EDM of tool stee EN 90MnCrV8 (W.-Nr. 1.2842) with Cu-ETP electrode EN CW004A and their assumed influence on EWR

\begin{tabular}{|c|c|}
\hline $\begin{array}{l}\text { Setting range of the } \\
\text { MTP }\end{array}$ & Influence of MTP on EWR \\
\hline $\begin{array}{l}\text { Peak current } \\
" I " I^{\prime \prime} 5.0-35.0 \mathrm{~A}\end{array}$ & $\begin{array}{l}\text { With increasing value of / rapidly } \\
\text { increase EWR. }\end{array}$ \\
\hline $\begin{array}{l}\text { Pulse on-time duration } \\
\text { " } t_{\text {on }} " 20.0-130.0 \mu \mathrm{s}\end{array}$ & $\begin{array}{l}\text { With increasing value of } t_{\text {on }} \text { it occurs to } \\
\text { the significant decrease of EWR. }\end{array}$ \\
\hline $\begin{array}{l}\text { Pulse off-time duration } \\
\text { " } t_{\text {off }}{ }^{\prime} 10.0-90.0 \mu \mathrm{s}\end{array}$ & $\begin{array}{l}\text { With increasing value of } t_{\text {off }} \text { it occurs } \\
\text { to the slight decrease of EWR. }\end{array}$ \\
\hline $\begin{array}{l}\text { Voltage of discharge } \\
\text { "U" 80.0-95.0 V }\end{array}$ & $\begin{array}{l}\text { With increasing value of } U \text { it occurs to } \\
\text { the gradual increase EWR. }\end{array}$ \\
\hline Gap “auto" & $\begin{array}{l}\text { Increasing the gap value leads to a } \\
\text { decrease in EWR. }\end{array}$ \\
\hline Flushing "upper rinse" & $\begin{array}{l}\text { With increasing of dielectric pressure } \\
\text { to decrease of EWR. }\end{array}$ \\
\hline Dielectric fluid "oil" & -- \\
\hline
\end{tabular}

From this overview is clear that the greatest expected effect on EWR of mentioned process parameters has peak current $I$ and pulse on-time duration $t_{o n}$. On the contrary, the least expected effect on EWR has pulse off-time $t_{\text {off }}$ and voltage of discharge $U$.

\section{EXPERIMENTAL EXECUTION AND RESULTS}

Based on the above theoretical analysis of the expected impact of the MTP in die-sinking EDM tool steel EN 90MnCrV8 (W.-Nr. 1.2842) with Cu-ETP tool electrode EN CW004A on EWR was considered in experiment with the impact of peak current, pulse on-time duration, pulse off-time duration and voltage of discharge. Effects of the peak current $I$ in the range of 5 to $35 \mathrm{~A}$ on EWR are shown on Fig. 4.

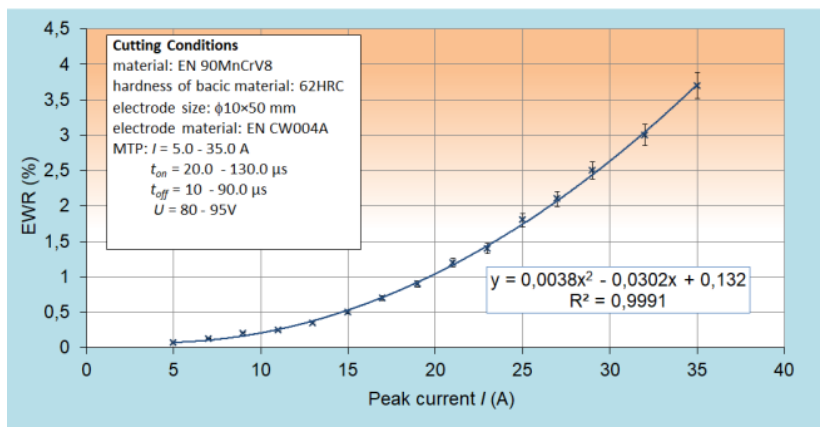

Figure 4: Influence of peak current $I$ in the range of 5 to 35A on EWR in die-sinking EDM of tool steel EN 90MnCrV8 (W.-Nr. 1.2842) with CuETP electrode EN CW004A

From the Fig. 4 can be in detail observed that with increasing value of peak current I in die-sinking EDM of tool steel EN 90MnCrV8 (W.-Nr. 1.2842) with Cu-ETP electrode EN CW004A is substantially increased the size of EWR. At the lowest value of peak current $I=5 \mathrm{~A}$ was achieved the lowest value of EWR $=0.07 \%$. Conversely, at the highest value of peak current $I=35 \mathrm{~A}$ was also achieved the highest value of $E W R=3.70 \%$. Effects of the pulse on-time duration $t_{\text {on }}$ in the range of 20 to $130 \mu$ s on EWR are shown on Fig. 5.

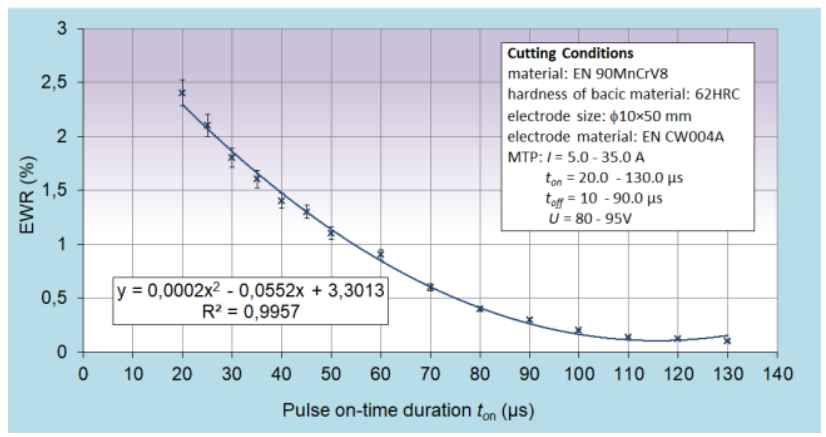

Figure 5: Influence of pulse on-time duration ton in the range of 20 to 130 us on EWR in die-sinking EDM of tool steel EN 90MnCrV8 (W.-Nr. 1.2842) with CU-ETP electrode EN CW004A

From the Fig. 5 can be in detail observed that with increasing value of pulse on-time duration ton in die-sinking EDM of tool steel EN 90MnCrV8 (W.-Nr. 1.2842) with Cu-ETP electrode EN CW004A it occurs to the significant decrease of EWR. At the lowest value of pulse on-time duration $t_{o n}=20 \mu$ s was achieved the highest value of EWR $=2.40 \%$. Conversely, at the highest value of $t_{o n}=130 \mu \mathrm{s}$ was achieved the lowest value of $E W R=0.10 \%$. Effects of the pulse off-time duration $t_{\text {off }}$ in the range of 10 to $90 \mu$ s on EWR are shown on Fig. 6 .

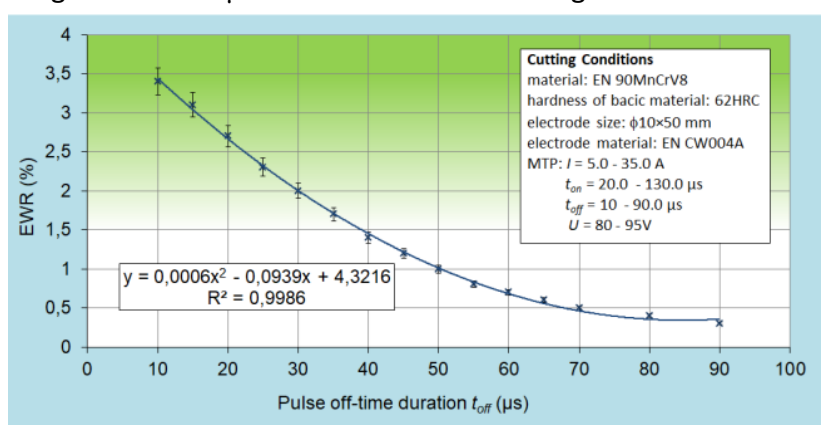

Figure 6: Influence of pulse off-time duration toff in the range of 10 to $90 \mu$ s on EWR in die-sinking EDM of tool steel EN 90MnCrV8 (W.-Nr. 1.2842) with CU-ETP electrode EN CW004A 
From Fig. 6 can be observed in detail that with increasing value of pulse off-time duration toff in die-sinking EDM of tool steel EN 90MnCrV8 (W.-Nr. 1.2842) with CU-ETP electrode EN CW004A it occurs to the slight decrease of EWR. At the lowest value of pulse off-time duration $t_{\text {off }}=10 \mu$ s was achieved the highest value of EWR $=3.40 \%$. Conversely, with the highest value of $t_{\text {off }}=90 \mu \mathrm{s}$ was achieved the lowest value of $E W R=0.30 \%$. Effects of the voltage of discharge $U$ in the range of 80 to $95 \mathrm{~V}$ on EWR are shown on Fig. 7.

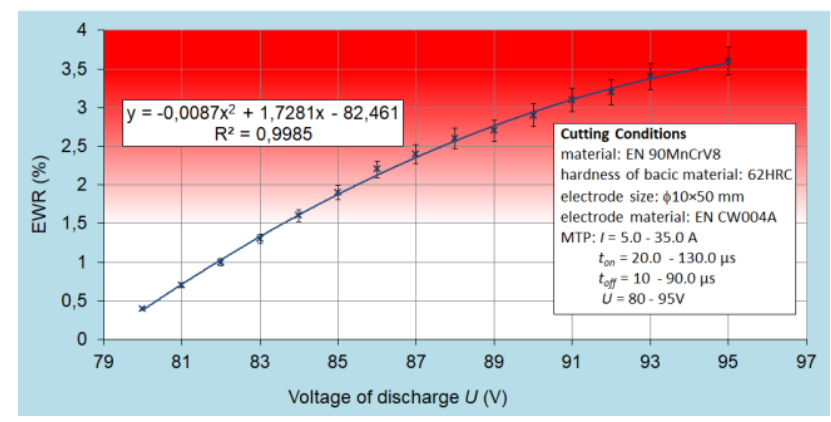

Figure 7: Influence of voltage of discharge $U$ in the range of 80 to $95 \mathrm{~V}$ on EWR in die-sinking EDM of tool steel EN 90MnCrV8 (W.-Nr. 1.2842) with CU-ETP electrode EN CW004A

From the Fig. 7 can be observed that with increasing value of voltage of discharge $U$ in die-sinking EDM of tool steel EN $90 \mathrm{MnCrV8}$ (W.-Nr. 1.2842) with Cu-ETP electrode EN CW004A it occurs to the gradual increase of EWR. At the lowest value of voltage of discharge $U=80 \mathrm{~V}$ was achieved the lowest value of $\mathrm{EWR}=0.40 \%$. Conversely, at the highest value of $U=95 \mathrm{~V}$ was achieved the highest value of EWR $=3.60 \%$.

Recommendation for machining tool steel EN 90MnCrV8 (W.Nr. 1.2842) with CU-ETP electrode EN CW004A by die-sinking EDM, in terms of choice the MTP [Stephen 2011], i.e. peak current $l$, pulse on-time duration ton, pulse off-time duration $t_{\text {off, }}$ and voltage of discharge $U$, is their optimisation [Tamang 2017] in view of the minimization of the parameter EWR [Salcedo 2017]. For achieving the minimum value EWR is required that the combination the MTP at which the parameters peak current $I$ and voltage of discharge $U$ will preferably acquire the lowest values [Kumar 2017]. Conversely, in choice of pulse on-time duration ton and pulse off-time duration $t_{\text {off }}$ it is necessary to choose the highest value. Of course, choosing of the MTP must necessarily to respect the stability [Straka 2014] and performance [Chen 2017] electroerosive process.

\section{CONCLUSIONS}

The Contribution aimed to describe the mechanism of material removal in the die-sinking EDM of tool steel EN 90MnCrV8 (W.Nr. 1.2842) with Cu-ETP electrode EN CW004A. One of the usually used parameters that quite accurately identifies mechanism of material removal in the die-sinking EDM is TWR. This parameter, however, describes only regularities concerning the wear of the tool electrode. EWR is more complex parameters, which in addition to the tool electrode wear size, describes the size of the MRR from workpiece. The particular value of EWR is substantially dependent on the type of electrode and workpiece material, but also on the setting of the MTP. Unsuitable mechanical, physical and chemical properties of materials [Zidek 2018], used for manufacturing tool electrodes, may adversely affect the value of EWR. The aim of the performed experiments was also to define the individual specifics with a view to minimizing the EWR. On the basis of the analysis were selected the MTP, which substantially affects the extent of the crater (shape and dimension) in the workpiece, but also in the tool electrode, and thus the parameter EWR.

When analysing, by relying on experimental results of measurements, was already identified a number of important facts:

- may be stated that in the die-sinking EDM of tool steel EN 90MnCrV8 (W.-Nr. 1.2842) with Cu-ETP electrode EN CW004A on the EWR mainly affects peak current $I$ and pulse on-time $t_{o n}$;

- to the size of the EWR has a much smaller effect the setting values of pulse off-time $t_{\text {off }}$ and voltage of discharge $U$;

- for achieving the minimum value EWR in the diesinking EDM is necessary optimization of the MTP;

- recommendations in the selection of the MTP in diesinking EDM the tool steel EN 90MnCrV8 (W.-Nr. 1.2842) with CU-ETP electrode EN CW004A in terms of minimizing the value is a choice of low values of peak current $I$ and voltage of discharge $U$. On the contrary, to minimize the parameter EWR is required the selection of higher levels of pulse on-time duration ton and pulse off-time $t_{\text {off. }}$ In the choice of mutual combination MTP, however, it should be taken into account the performance, stability and efficiency of the die-sinking EDM process.

\section{ACKNOWLEDGMENTS}

The authors would like to thank the grant agency for supporting research work the project VEGA 1/0205/19.

\section{REFERENCES}

[Banker 2013] Banker, K.S., Parmar, S.P. and Parekh B.C. Review to Performance Improvement of Die Sinking EDM Using Powder Mixed Dielectric Fluid. International Journal of Research in Modern Engineering and Emerging Technology, 2013, Vol. 1, pp. 57-62.

[Baron 2016] Baron, P., Zajac, J. and Pollak, M. The correlation of parameters measured on rotary machine after reparation of disrepair state. MM Science Journal, 2016, No. 11, pp. 12441248.

[Botko 2019] Botko, F. et al. Influence of Residual Stress Induced in Steel Material on Eddy Currents Response Parameters. Advances in Manufacturing II, Vol. 4, pp. 551-560, ISBN 978-3-030-16942-8.

[Corny 2016] Corny, I. Overview of progressive evaluation methods for monitoring of heat production and distribution. Procedia Engineering, 2016, Vol. 190, pp. 619-626.

[Dubjak 2016] Dubjak, J., Pitel, J. and Tothova, M. Diagnostics of aluminum alloys melting temperature in high pressure casting. Key Engineering Materials, 2016, Vol. 669, pp. 110-117. [Han 2016] Han, X.L. et al. Influence of Post-Weld Heat Treatment on the Microstructure, Microhardness, and Toughness of a Weld Metal for Hot Bend. Metals, 2016, Vol. 6, doi:10.3390/met6040075.

[Hasova 2016] Hasova, S. and Straka, L. Design and verification of software for simulation of selected quality indicators of machined surface after WEDM. Academic Journal of Manufacturing Engineering, 2016, Vol. 14, No. 2, pp. 13-20.

[Chen 2017] Chen, T. et al. Study on test method of white layer microhardness in hard cutting based on chord tangent method. International Journal of Advanced Manufacturing Technology, 2017, Vol. 92, No. 1-4, pp. 733-741. 
[Kiyak 2007] Kiyak, M. and Cakir, O. Examination of machining parameters on surface roughness in EDM of tool steel. Journal of Materials Processing Technology, 2007, Vols. 1-3, pp. 41-44. [Krenicky 2011] Krenicky, T. Implementation of Virtual Instrumentation for Machinery Monitoring. In: Operation and Diagnostics of Machines and Production Systems, Lüdenscheid, RAM-Verlag, 2011, pp. 5-8.

[Kumar 2017] Kumar, R.A., Saurav, D., Bibhuti, B.B. and Siba, S.M. Machining performance optimization for electro-discharge machining of Inconel 601, 625, 718 and 825: an integrated optimization route combining satisfaction function, fuzzy inference system and Taguchi approach. Journal of the Brazilian Society of Mechanical Sciences and Engineering, 2017, Vol. 39, pp. 3499-3527.

[Luis 2005] Luis, C.J., Puertas, I. and Villa, G. Material removal rate and electrode wear study on the EDM of silicon carbide. J. Material Processing Technology, 2005, Vol.164-165, pp. 889896.

[Malega 2017] Malega, P. Simulation of production systems as the effective tool of efficiency increasing. Interdisciplinarity in Theory and Practice, 2017, Vol. 12, pp. 17-22.

[Mathew 2014] Mathew, S., Varma, P.R.D. and Kurian, P.S. Study on the Influence of process parameters on surface roughness and MRR of AISI 420 stainless steel machined by EDM. International Journal of Engineering Trends and Technology, 2014, Vol. 2, pp. 54-58.

[Micietova 2013] Micietova, A., Neslusan, M. and Cillikova, M. Influence of surface geometry and structure after nonconventional methods of parting on the following milling operations. Manufacturing Technology, 2013, Vol. 13, pp. 199204.

[Michalik 2016] Michalik, P., Zajac, J., Hatala, M., Duplak, J. and Mital, D. Comparison of programming production of thin walled parts using different CAM systems. MM Science Journal, 2016, Vol. 10, pp. 1056-1059.

[Monka 2016] Monka, P.P. et al. Design and experimental study of turning tools with linear cutting edges and comparison to commercial tools. The International Journal of Advanced Manufacturing Technology, 2016, Vol. 85, No. 9-12, pp. 23252343.

[Murcinkova 2013] Murcinkova, Z. and Krenicky, T. Implementation of virtual instrumentation for multiparametric technical system monitoring. In: SGEM 2013: 13th Int. Multidisciplinary Sci. Geoconf. Vol. 1: 16-22 June, 2013, Albena, Bulgaria. Sofia: STEF92 Technology, 2013. pp. 139-144. ISBN 978-954-91818-9-0.

[Panda 2014] Panda, A., Prislupcak, M. and Pandova, I. Progressive technology diagnostic and factors affecting to machinability. Applied Mechanics and Materials, 2014, Vol. 616, pp. 183-190.

[Panda 2016] Panda, A., Duplak, J., Hatala, M., Krenicky, T. and Vrabel, P. Research on the durability of selected cutting materials in the process of turning carbon steel. MM Science Journal, 2016, Vol. 10, pp. 1086-1089.

[Rimar 2016] Rimar, M., Fedak, M., Kulikov, A. and Smeringai, $P$. Dependence of hardness of continues die-casting products on Fe content. MM Science Journal, 2016, Vol. 11, pp. 12011204.

[Salcedo 2017] Salcedo, A.T., Arbizu, P.I. and Perez, C.J.L. Analytical modelling of energy density and optimization of the EDM machining parameters of inconel 600. Metals, 2017, Vol. 7, No. 5, pp. 166.

[Singh 2004] Singh, S., Maheshwari, S. and Pandey, P.C. Some investigations into the electric discharge machining of hardened tool steel using different electrode materials. Journal of Material Processing Technology, 2004, Vol. 149, pp. 272-277.
[Soni 1995] Soni, J.S. and Chakraverti, G. Effect of electrode material properties on surface roughness and dimensional accuracy in electro-discharge machining of high carbon high chromium die steel. Journal of Industrial Engineering, 1995, Vol. 76, pp. 46-51.

[Stephen 2011] Stephen, P., Radzevich, P.S. and Krehel, R. Application priority mathematical model of operating parameters in advanced manufacturing technology. The International Journal of Advanced Manufacturing Technology, 2011, Vol. 56, No. 2, pp. 835-840.

[Straka 2013] Straka, L., Corny, I. and Krehel, R. Evaluation of capability of measuring device on the basis of diagnostics. Applied Mechanics and Materials, 2013, Vol. 308, pp. 69-74.

[Straka 2014] Straka, L. Analysis of Wire-Cut Electrical Discharge Machined Surface. LAP Lambert Academic Publishing, Germany, 2014, 98 p.

[Straka 2016a] Straka, L. and Hasova, S. Prediction of the heataffected zone of tool steel EN X37CrMoV5-1 after die-sinking electrical discharge machining. Proc Inst. Mech. B: J. Eng. Manuf., 2016, Vol. 9, pp. 1-12.

[Straka 2016b] Straka, L. and Hasova, S. Assessing the influence of technological parameters on the surface quality of steel MS1 after WEDM. MM Science Journal, 2016, Vol. 11, p. 1194-1200. [Straka 2016c] Straka, L. and Hasova, S. Study of tool electrode wear in EDM process. Key Engineering Materials, 2016, Vol. 669, pp. 302-310.

[Straka 2016d] Straka, L., Corny, I. and Pitel, J. Properties evaluation of thin microhardened surface layer of tool steel after wire EDM. Metals, 2016, Vol. 6, No. 5, pp. 1-16.

[Straka 2017] Straka, L., Corny, I., Pitel, J. and Hasova, S. Statistical Approach to Optimize the Process Parameters of HAZ of Tool Steel EN X32CrMoV12-28 after Die-Sinking EDM with SF-Cu Electrode. Metals, 2017, Vol. 7, No. 2, pp. 1-22.

[Świercz 2017] Świercz, R. and Oniszczuk-Świercz, D. Experimental Investigation of Surface Layer Properties of High Thermal Conductivity Tool Steel after Electrical Discharge Machining. Metals, 2017, Vol. 7, No. 12, p. 550.

[Tamang 2017] Tamang, S.K., Natarajan, N. and Chandrasekaran, M. Optimization of EDM process in machining micro holes for improvement of hole quality. The Journal of the Brazilian Society of Mechanical Sciences and Engineering 2017, Vol. 39, pp. 1277-1287.

[Tavodova 2014] Tavodova, M. Research state heat affected zone of the material after wire EDM. Acta Facultatis Technicae, 2014, Vol. 19, pp. 145-152.

[Tothova 2015] Tothova, M., Balara, M. and Dubjak, J. Simulation model of cascade control of the heating system. International Journal of Engineering Research in Africa, 2015, Vol. 18, pp. 20-27.

[Zidek 2018] Zidek, K., Vasek, V., Pitel, J. and Hosovsky, A. Auxiliary device for accurate measurement by the smartvision system. MM Science Journal, 2018, No. March, pp. 2136-2139, ISSN 1803-1269.

\section{CONTACTS}

assoc. prof. Ing. Luboslav Straka, PhD.

Ing. Gabriel Dittrich

Department of Automotive and Manufacturing Technologies Faculty of Manufacturing Technologies

Technical University of Košice with a seat in Presov,

Sturova 31, 08001 Presov, Slovakia

Tel.:+421556026365

e-mail: luboslav.straka@tuke.sk, gabriel.dittrich@tuke.sk 